\title{
The Impact of the Listener's Gender on the Frequency and Diversity of the English Audible Backchannels
}

Received: 25/09/2019 ; Accepted: 09/12/2019

\section{Abstract}

This article deals with backchannels in relation to the listener's gender. Being comparative, it aims to find the similarities and differences between males and females when it comes to backchannels. To do so, 30 male and 30 female students of English, at university Frères Mentouri 1, Constantine, took part in the study; each male recorded a face-to-face two-minute conversation with a female. After analyzing the conversations, the results revealed that the frequency of the females' different backchannels' occurrence was higher than the males'. This endorses what the previous studies concluded: when listening, females react more than males. Concerning the backchannels' diversity, neither the males nor the females equally diversified their backchannels since both highly used the acknowledging utterances; therefore, the other categories did not noticeably stand out; what forcefully denotes the students' unawareness of those categories. Accordingly, it is of necessity to thoroughly highlight the skill of active listening to make students of English competent communicators.

Keywords: Gender, The Frequency of Backchannels' Occurrence, The Diversity of Backchannels, Active Listening

\section{Bachir HABALET *}

Université des Fréres Mentouri-Constantine

\section{Résumé}

L'article examine la relation entre les "backchannels" et le sexe de l'auditeur. Ayant une nature comparative, la thèse essaye de trouver les similarités et les différences entre les garçons et les filles en relation avec les "backchannels." la comparaison est basée sur deux critères : la fréquence d'occurrence et la diversité des "backchannels." Deux hypothèses ont été développées pour vérifier leur validité : (1) par rapport aux garçons, les filles font plus en écoutant et (2) les réactions des filles sont plus variées que les réactions des garçons. Un échantillon de 60 étudiants de sous-graduation (30 garçons et 30 les filles) ont fait partie de l'étude. On a demandé à chaque homme d'enregistrer une conversation face-à-face avec une femme qui durait jusqu'à 2 minutes. Après l'analyse des conversations de genre mixte, les résultats ont révélé que la fréquence d'occurrence des "backchannels" des femmes a été plus haute que celle des. Celui-là approuve la conclusion des études antérieures et valide la première hypothèse. En ce qui concerne la diversité des "backchannels," ni les garçons ni les filles n'ont diversifié leurs "backchannels" également, et cela prouve que la deuxième hypothèse est incorrecte. Tous les deux ont fortement utilisé les expressions d'approbation. Par conséquent, les autres catégories ont été marginalement utilisées par les deux groupes. Il est nécessaire d'adresser les différents types des "backchannels" lors des sessions d'expression orale.

Mots clés: Le sexe, La Fréquence d'Occurrence des "Backchannels", La Diversité des "Backchannels"eee, Les Expressions d'Approbation

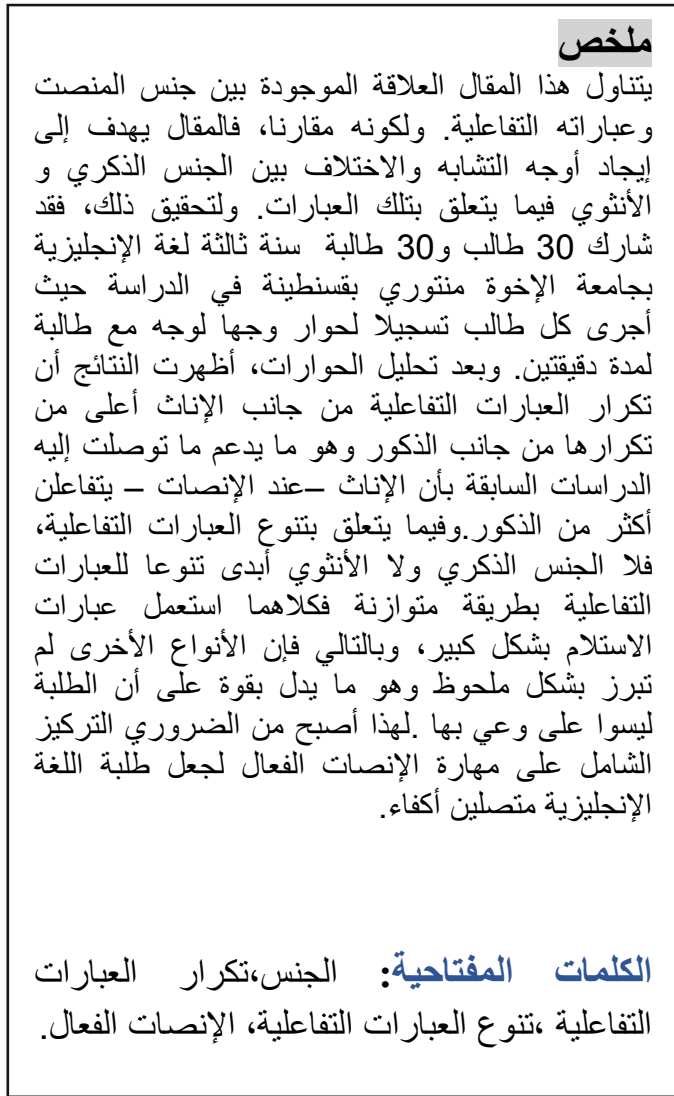

* Corresponding author, e-mail: bachirhabalet@gmail.com 


\section{Introduction}

Scholars have overwhelmingly been devoted to communication. Yule (2010) asserted that communication is so indispensable that human beings cannot do without. Being pervasive, it takes place everywhere: at home, at school, at work, and so forth. One of the most prominent forms of communication is face-to-face conversation. Despite the fact that it is not straightforward to satisfactorily characterize a conversation, Orestrom (1983) defines it as a speech event that does not only entail reciprocal exchange of information, but feelings and opinions as well. In a similar vein, Keller and Warner (1988) point out, "Conversation is like a game of football. One player can only run with the ball in one direction for a certain time. Sooner or later he must change direction or pass the ball to another player'" (p. 35).

The centrality of conversation has, for a long time, grabbed the attention of some conversation analysists who have thoroughly approached conversation styles in relation to a number of social and psychological factors: native language, context, culture, and gender. Since the latter, along with backchannels, constitutes the kernel of the article, it is requisite to review some previous works.

Tannen (1990) believes that gender differences in conversation are the outcome of the different perspectives males and females have in conversation. According to her, females, characterized by collaborative trait, prefer a give-and-take style. Accordingly, when listening, they use supportive utterances. Males, by contrast, are, as Holmes (1995) describes, competitive in the sense that they tend to interrupt others so frequently. In the same context, Yule (2010) claims, "In cross-gender interactions, men are much more likely to interrupt women, with 96 percent of the identified interruptions being attributed to men in one study involving American college students" (p. 277). It is another way to say that males tend to utter fewer backchannels (Maltz \& Borker, 1982).

Gender differences, Uchida (1992) asserts, are due to the difference theory which suggests that men and women live in different cultural planets and, therefore, they develop different communication styles. Another work to be mentioned about backchannels is Furo's (1999). She related backchannels to both language and gender. After analyzing male and female conversations of Japanese and Americans, she came to this conclusion: backchannels occur more pervasively in Japanese than in English. She also found that Japanese females backchannelled more than males did. This article is, once more, an attempt to see the impact of gender on the use of the English backchannels. The study is motivated by the importance of active listening in making conversations successful. Keller and Warner (1988) state, "we expect other people to respond to us. How they respond tells us how to develop what we say. This means that successful conversations depend partly on how we respond to what other people say" (p. 61). Zimmermann (1991) adds that to be an engaged, supportive, and tactful listener, one should exhibit an interest toward the speaker's utterances. This is achieved through the use of backchannels (the term backchannels was first used by Yngve (1970).

According to Hey and Holloway (2015), a backchannel signal stands for " a sound or sign that somebody makes to show that they are listening to the person who is talking to them" (p. 94). On the same wavelength, explaining the term 'backchannels', White (1989) says that the 'back' channel refers to the addresser talk who gives feedback without asking for the floor. Although scholars have given backchannels many alternatives: response tokens (Gardner, 2001), minimal responses (Fellegy, 1995), and reactive tokens (Young, 2004), they have all stressed their importance. "If the speaker would not be given such a feedback and only silence would be present, he would start to think that no attention to what he utters is paid and the flow of converasation would be disrupted"' (Pipek, 2007, p. 11).

Taking all the aforementioned contributions in mind, it is worth to say, once again, that this article investigates how gender affects one of the conversation building blocks, notably backchannels. More precisely, the article aims at comparing the different 
categories of the males' backchannels and the females'ones on the basis of two factors: the frequency of their occurrence and their diversity. Concerning the categories of backchannels adopted in this article, they refer to those Gardner (1994) distinguishes: acknowledgement, assessment, continuers, collaborative repetition/ completion, the news marker Really?, and non-verbal vocalizations (as cited in Thornbury\&Slade, 2006, p. 132).

\section{Method and Sampling}

As conversation analysts have always been overwhelmingly interested in the different aspects of spoken interaction, it was of central necessity to adopt audio recording to collect the required data. Pridham (2001) points out, "the only way to conduct research on conversation is to tape it...' (p. 7). The participants of the study consisted of 60 third year students belonging to the Department of English, University Frères Mentouri, Constantine. They were randomly selected. The reason behind choosing third year students goes to the fact that students, at this level, can be said to be able to conduct a short conversation in English. Moreover, one has to bear in mind that the participants did share the same culture, the Algerian culture; status, students of English; and age, 21-25, but not gender.

The participants were equally divided into males and females, where each two participants conducted a mixed-gender two minute face-to-face English conversation. In order to secure fluency and minimize their inhibition, the participants were allowed to speak about any topic, choose their counterparts, and most importantly, record themselves. After collecting and, then, transcribing the participants' recorded conversations, the males' and the females' backchannelling utterances were highlighted and tabulated in accord with the Gardner's classification of the different ways of exhibiting engaged listenership.

\section{Results and Discussion}

In the beginning, the study posed a number of questions. One of them was whether female Algerian students really backchannel more than males when using English as a foreign language. All through the 30 mixed-gender conversations conducted by the participants, the findings disclosed that females truly backchannel more than males do. The following table reveals the number of the English backchannels uttered in each conversation: 


\begin{tabular}{|c|c|c|}
\hline The Conversation & $\begin{array}{c}\text { The Number of } \\
\text { Backchannels Uttered by } \\
\text { the Female }\end{array}$ & $\begin{array}{c}\text { The Number of } \\
\text { Backchannels Uttered by } \\
\text { the Male }\end{array}$ \\
\hline Conversation1 & 13 & 06 \\
\hline Conversation 2 & 11 & 09 \\
\hline Conversation 3 & 05 & 03 \\
\hline Conversation 4 & 00 & 04 \\
\hline Conversation 5 & 03 & 03 \\
\hline Conversation 6 & 00 & 04 \\
\hline Conversation 7 & 03 & 05 \\
\hline Conversation 8 & 06 & 06 \\
\hline Conversation 9 & 05 & 06 \\
\hline Conversation 10 & 02 & 00 \\
\hline Conversation 11 & 06 & 03 \\
\hline Conversation 12 & 13 & 01 \\
\hline Conversation 13 & 14 & 00 \\
\hline Conversation 14 & 04 & 04 \\
\hline Conversation 15 & 02 & 07 \\
\hline Conversation 16 & 05 & 01 \\
\hline Conversation 17 & 06 & 05 \\
\hline Conversation 18 & 01 & 01 \\
\hline Conversation 19 & 02 & 01 \\
\hline Conversation 20 & 20 & 02 \\
\hline Conversation 21 & 09 & 09 \\
\hline Conversation 22 & 01 & 02 \\
\hline Conversation 23 & 00 & 03 \\
\hline Conversation 24 & 06 & 05 \\
\hline Conversation 25 & 01 & 02 \\
\hline Conversation 26 & 09 & 03 \\
\hline Conversation 27 & 05 & 03 \\
\hline Conversation 28 & 21 & 02 \\
\hline Conversation 29 & 05 & 00 \\
\hline Conversation 30 & 00 & 00 \\
\hline The Total Number & 178 & 100 \\
\hline
\end{tabular}

Table 1: The Number of Backchannels Uttered by the Participants in Each Conversation

Having a glance at table 1, of all the 278 backchannels, 178 of them were uttered by the females, while 100 were used by the males. Elaborately, the table also indicates that in 17 out of 30 conversations, the female participants were more observant than the male ones. This, one can assertively state, does parallel the conclusion of an American study that when playing the role of listening, women are more attentive than men (Tannen, 1990). The reason why the Algerian females backchannel more than the males can go back to what Basow \& Rubenfield (2003) assume that females, as opposed to males, are known for being more expressive, tentative, and tactful in conversation.

What the table, above, also embraces is that both the female and male participants did not, most often, remain silent when listening. That is to say, they were speaking listeners. This finding was to back up the fact that listeners listen by speaking (Farr, 2003). .

Since this article is purely comparative, it has been central to go in deep, and examine the different categories of engaged listenership in relation to gender. The following table goes back to the categories of backchannels adopted by the participants in their conversations: 


\begin{tabular}{|c|c|c|c|c|c|c|}
\hline Categories & $\begin{array}{c}\text { Aknowledging } \\
\text { Utterances }\end{array}$ & $\begin{array}{c}\text { Assessing } \\
\text { Utterances }\end{array}$ & Continuers & $\begin{array}{c}\text { The } \\
\text { News } \\
\text { Marker } \\
\text { Really? }\end{array}$ & $\begin{array}{c}\text { Collaborative } \\
\text { Repetitive/ } \\
\text { Completive } \\
\text { Utterances }\end{array}$ & $\begin{array}{c}\text { Non- } \\
\text { Verbal } \\
\text { Vocaliz } \\
\text { ations }\end{array}$ \\
\hline Females & 102 & 23 & 13 & 05 & 17 & 18 \\
\hline Males & 61 & 16 & 03 & 02 & 14 & 04 \\
\hline
\end{tabular}

Table 2: The Frequency of Occurrence of the Different Categories of Backchannels

Table 2 exhibits much information. First, the females and the males were different in terms of the frequency of occurrence of each category adopted. All the females' categories were more pervasive than the males' $(61<102,16<23,3<13$, $02<05,14<17,4<18)$. This, once again, answers the question: Do Algerian females backchannel more than males when using English as a foreign language?

Apart from what is different, it can clearly be observed that neither the females nor the males used the categories in an equal manner. Despite the fact that all the categories were put into effect, they were unequally distributed by both the female and the male participants. Gender, therefore, does not really account for the distribution of backchannels as the participants, to such an extent, adhered to the acknowledging category. The 163 acknowledging utterances are elaborated in the following table :

\begin{tabular}{|c|c|c|c|}
\hline $\begin{array}{l}\text { The } \\
\text { Acknowledging } \\
\text { Utterances }\end{array}$ & $\begin{array}{l}\text { The } \\
\text { Number }\end{array}$ & $\begin{array}{l}\text { The Total Number } \\
\text { Uttered by the Females }\end{array}$ & $\begin{array}{l}\text { The Total Number } \\
\text { Uttered by the Males }\end{array}$ \\
\hline Yeah & 106 & 65 & 41 \\
\hline Okay & 32 & 19 & 13 \\
\hline Of course & 11 & 07 & 04 \\
\hline Indeed & 02 & 02 & l \\
\hline Exactly & 05 & 05 & 1 \\
\hline Absolutely & 01 & 01 & 1 \\
\hline Alright & 02 & 01 & 01 \\
\hline Sure & 01 & 01 & l \\
\hline$M m$ & 01 & 01 & 1 \\
\hline Right & 01 & I & 01 \\
\hline I think that too & 01 & I & 01 \\
\hline
\end{tabular}

Table 3: The Acknowledging Utterances Adopted by the Participants

Table 3 shows that the females exhibited greater attentiveness. As noticed, not only did females adopted more different utterances, but their acknowledging utterances (yeah, okay, of course) outnumber the males'. Concerning the most frequent acknowledging utterances, table 3 reveals that the participants, apart from their gender, were glued to yeah (this utterance represents $63,72 \%$ of all the females' acknowledging utterances and $67,21 \%$ of the males'). This parallels this fact: based on a 3-million-word sample of the 5-million-word CANCODE spoken corpus, yeah was found one of the 10 most frequent words (McCarthy, 1999).

Concerning the pervasive adoption of yeah by the participants, the reason can be attributed to the fact that yeah is one of the first words they learn when being exposed to English as a foreign language..

An important point to be raised concerning yeah is that it should not always be treated as a backchannelling signal. Backchannels, by nature, are spontaneous utterances. It means that they only take place when the listener is not forced to react. In the following excerpt taken from one of the participants' conversations, yeah does not acknowledge, but answers the previous speaker's utterance:

Female: So, is this song a good one? 
Male: $\underline{Y E A H}$, one of the best he ever sang.

Another comparison should be made at another level, assessment. The table below exhibits the adjectives the participants uttered to assess each other.

\begin{tabular}{|l|l|c|c|}
\hline $\begin{array}{l}\text { The Assessing } \\
\text { Adjectives }\end{array}$ & The Total Number & $\begin{array}{l}\text { The Total Number } \\
\text { Uttered by the Total Number } \\
\text { Females }\end{array}$ & $\begin{array}{l}\text { The } \\
\text { Uttered by the } \\
\text { Males }\end{array}$ \\
\hline Good & 16 & 09 & 07 \\
\hline Bad & 03 & 03 & 03 \\
\hline Right & 06 & 03 & 01 \\
\hline True & 03 & 02 & 01 \\
\hline Interesting & 03 & 02 & 01 \\
\hline Nice & 02 & 01 & $/$ \\
\hline Fun & 01 & 01 & $/$ \\
\hline Typical & 01 & 01 & 01 \\
\hline Happy & 01 & 01 & 01 \\
\hline Great & 01 & $/$ & 01 \\
\hline Accurate & 01 & $/$ & $/$ \\
\hline Fine & 01 & $/$ & ( \\
\hline
\end{tabular}

Table 4: The Assessing Adjectives Adopted by the Participants

Table 4 is similar to the previous one, in the sense that the females assessed more than the males did. While the former assessed the speaker 23 times, the latter assessed 16 times. Moreover, although the participants uttered different adjectives to assess each other, they, once again, did not use them equally. Thus, the most pervasive adjective adopted by the participants, as table 4 displays, was good (this represents 39, $13 \%$ of all the females' assessing adjectives and $43,75 \%$ of the males'). The reason can be attributed to the fact that the adjective good is embedded in the idiosyncrasy of the participants.

Another class of showing engaged listenership are continuers. The following table goes back to the participants' continuers:

\begin{tabular}{|l|c|c|}
\hline The Conversations & The Females' Continuers & The Males' Continuers \\
\hline Conversation 8 & 3 & $/$ \\
\hline Conversation 12 & 4 & 1 \\
\hline Conversation 17 & $/$ & 1 \\
\hline Conversation 20 & 2 & 1 \\
\hline Conversation 27 & 1 & $/$ \\
\hline Conversation 28 & 3 & 03 \\
\hline Total & 13 & (13) \\
\hline
\end{tabular}

Table 5: The Frequency of Occurrence of the Continuers by the Female and Male Participants

These, compared to the first classes (acknowledgement and assessments), were not prominent. To illustrate, only 13 times did the females show listening via $u h$ - huh or mmhm. In addition, the 13 continuers, representing $7,3 \%$ of all the females' backchannels, occurred in 5 conversations (C8, C12, C20, C27, and C28). In a similar vein, but to a lesser extent, the males uttered 3 continuers (representing $3 \%$ of all their backchannels) in 3 conversations $(\mathrm{C} 12, \mathrm{C} 17$, and $\mathrm{C} 20)$. This basically means that, for the most part, students of English do not make use of continuers to portray their attentiveness. The reason might be the students' ignorance due to the lack of exposure to utterances like $u h \mathrm{huh}$ and $\mathrm{mmhm}$.

Another angle from which the females' and the males' behaviour can be seen is the use of the news marker Really? The following table summarizes the use of this news marker by the participants: 
The Impact of the Listener's Gender on the Frequency and Diversity of the English Audible Backchannels

\begin{tabular}{|l|c|c|}
\hline \multirow{2}{*}{ The Conversations } & \multicolumn{2}{|c|}{ The News Marker Really? } \\
\cline { 2 - 3 } & Uttered by Females & Uttered by Males \\
\hline C5 & 01 & 00 \\
\hline C11 & 01 & 01 \\
\hline C14 & 00 & 01 \\
\hline C16 & 00 & 00 \\
\hline C17 & 01 & 00 \\
\hline C24 & 01 & $02(02 \%)$ \\
\hline $\begin{array}{c}\text { C26 } \\
\text { The Total Number } \\
\text { (Percentage) }\end{array}$ & 01 & \\
\hline
\end{tabular}

Table 6: The Frequency of Occurrence of Really? Uttered by the Female and the Male Participants

The news marker Really?, as shown, was not pervasively adopted by the participants. It was uttered 5 times by the females, representing an insignificant percentage $(2,79 \%$ of all their backchannels). The males also did not use Really? very frequently; they uttered it twice (representing $2 \%$ ). It can be said that rarely do students of English show surprise and, therefore, concern via the reactive question Really?

Another key category of listening actively is collaboration with the one taking the floor. Collaboration can be exhibited by means of completing or repeating the current speaker's utterance. In fact, collaboration is highly required by students of English who need to support each other when conducting a conversation using a language that is not theirs.

The following is a review of how the participants collaborate with each other:

\begin{tabular}{|l|c|c|c|c|}
\hline \multicolumn{1}{|c|}{ Gender } & \multicolumn{2}{|c|}{ F } & \multicolumn{2}{c|}{ M } \\
\hline $\begin{array}{l}\text { The Collaborative } \\
\text { Utterances }\end{array}$ & $\begin{array}{c}\text { Repetitive } \\
\text { Utterances }\end{array}$ & $\begin{array}{c}\text { Completive } \\
\text { Utterances }\end{array}$ & $\begin{array}{c}\text { Repetitive } \\
\text { Utterances }\end{array}$ & $\begin{array}{c}\text { Completive } \\
\text { Utterances }\end{array}$ \\
\hline C1 & 00 & 03 & 01 & 01 \\
\hline C2 & 01 & 00 & 00 & 00 \\
\hline C3 & 00 & 01 & 00 & 01 \\
\hline C6 & 00 & 00 & 01 & 00 \\
\hline C8 & 00 & 00 & 04 & 00 \\
\hline C9 & 00 & 01 & 01 & 00 \\
\hline C11 & 01 & 00 & 00 & 00 \\
\hline C12 & 02 & 00 & 00 & 00 \\
\hline C13 & 02 & 01 & 00 & 00 \\
\hline C14 & 01 & 00 & 01 & 00 \\
\hline C15 & 00 & 01 & 00 & 00 \\
\hline C17 & 01 & 00 & 00 & 00 \\
\hline C20 & 00 & 01 & 00 & 00 \\
\hline C21 & 00 & 00 & 00 & 03 \\
\hline C26 & 00 & 00 & 01 & 00 \\
\hline C28 & 01 & 00 & 00 & 00 \\
\hline Total (percentage\%) & $09(5,05 \%)$ & $08(4,49 \%)$ & $09(9 \%)$ & $05(5 \%)$ \\
\hline
\end{tabular}

Table 7: The Frequency of Occurrence of the Repetitive and Completive Utterances by the Female and Male Participants 
As far as collaborative repetition is concerned, the participants showed great likeness. When listening, the females repeated the males's utterances 9 times in 7 conversations $(\mathrm{C} 2, \mathrm{C} 11, \mathrm{C} 12, \mathrm{C} 13, \mathrm{C} 14, \mathrm{C} 17$, and $\mathrm{C} 28)$ where the males reiterated the females' 9 times in 6 conversations $(\mathrm{C} 1, \mathrm{C} 6, \mathrm{C} 8, \mathrm{C} 9, \mathrm{C} 14$, and $\mathrm{C} 26)$. Compared to acknowledgement and assessment, collaborative repetition was not prominently adopted by the participants.

It is of great importance to say that repetition that a participant adopts to gain the floor should not be viewed as a reactive token. Pipek (2007) ascertains "... backchannels do not purloin the speaker's floor, which is a current right to speak in a conversation" (p. 11). In the following example, the listener takes the floor by repeating the previous speaker's words:

A: What happened last week?

B: What happened last week was that I lost my car's keys.

Concerning completion, table 7 indicates that the participants showed little collaboration. The females completed the males' utterances 8 times in 6 conversations. The males, however, completed the females' utterances 5 times in 3 conversations. The reason behind this little interest in repeating and completing the speaker's utterances might be the hesitation of the participants.

In fact, active listening is not only mirrored by linguistic cues, but para-linguistic ones as well. Laughter was the only para-linguistic backchannel the participants adopted. As the table below indicates:

\begin{tabular}{|c|c|c|}
\hline $\begin{array}{l}\text { Conversation } \\
\text { Gender }\end{array}$ & $\begin{array}{c}\text { The Females's Non- } \\
\text { Verbal Vocalization } \\
\text { [Laughter] }\end{array}$ & $\begin{array}{c}\text { The Males' Non-Verbal } \\
\text { Vocalizations [ Laughter] }\end{array}$ \\
\hline Conversations 1 & 1 & $/$ \\
\hline Conversation 2 & 1 & $/$ \\
\hline Conversation 8 & 1 & $/$ \\
\hline Conversation 9 & 1 & $/$ \\
\hline Conversation 10 & 2 & $/$ \\
\hline Conversation 12 & 2 & $/$ \\
\hline Conversation 13 & 1 & $/$ \\
\hline Conversation 15 & $/$ & $/$ \\
\hline Conversation 17 & 1 & 1 \\
\hline Conversation 18 & 1 & $/$ \\
\hline Conversation 20 & 2 & 04 \\
\hline Conversation 21 & 2 & $/$ \\
\hline Conversation 26 & 1 & 1 \\
\hline Conversation 27 & 1 & 1 \\
\hline Conversation 28 & 1 & 1 \\
\hline Total & 18 & 1 \\
\hline
\end{tabular}

Table 8: The Frequency of Occurrence of the Non-Verbal Vocalization- Laughterby the Female and Male Participants

The results, table 8 suggests, revealed that when listening, the females laughed 18 times in 14 conversations, while the males 4 times in 4 conversations. The fact that the female participants laughed more than the male ones mirrors the language of rapport that females, in general, are characterized by. Apart from gender, laughter represents insignificant percentages $(10,11 \%$ of all the females' backchannels and $4 \%$ of the males'). The underlying assumption is that students of English do not usually make use of paralinguistic cues to indicate engaged listenership. 


\section{Limitations of the Article}

This article accounts for a study that was undertaken to approach the English backchannels in relation to gender. Much research needs to be done on how other factors as age, social status, the participant' personality, dialect, the context formality or informality, and the degree of intimacy govern the backchannelling behaviour. It has to be stressed that the classification of the backchannels in this article is attributed to Gardner's (1994) which only houses audible backchannels. In fact, it is immensely worthwhile tackling silent backchannels (eye contact, head nodding, and smiles). The study is also quantitatively simplified, in the sense that it held a smaller range of conversations where only two participants were involved in each. Future studies on conversations can also be carried out taking a large number of conversations and participants.

\section{Conclusion}

The article probed the backchannelling behaviour of Third Year Students of English at University Frères Mentouri, Constantine. It was an attempt to see the nature of the listening reactions of the students when conversing with different-gender partners. It also aimed at comparing the females' and the males' backchannels in relation to their frequency of occurrence and their diversity. The findings obtained after analyzing thirty mixed-gender conversations revealed a number of similarities and differences.

As far as the backchannels' frequency of occurrence is concerned, there was a decided difference between males and females. The latter was found to backchannel more than the former, which backs up the conclusion of the previous studies. Going in deep, compared to the males, the females showed higher tendency to acknowledge, assess, repeat, complete, vocalize, utter really? and adopt continuers. Females can, accordingly, be said that they are truly collaborative when it comes to interaction via a foreign language. This result, in fact, does validate this: gender governs the frequency of the English backchannels 'occurrence.

The similarities lie in the fact that both the females and males fiercely stuck to acknowledgement (yeah in particular). It means that both unequally diversified the use of backchannels, and rarely used some (continuers, for example). This significant finding denotes that gender does not really govern the diversity of the English backchannels. 


\section{References}

Basow, S. A., \& Rubenfeld, K. (2003). Troubles talk: Effects of gender and gender typing.

Farr, F. (2003). Engaged listenership in spoken academic discourse: The case of student-tutor meetings. Journal of English for Academic Purposes 2:67- 85.

Fellegy, Anna M. (1995). Patterns and functions of minimal response. American Speech 70:186- 199.

Furo, H. (1999). Listening responses in Japanese and US English: Gender and social interaction. In B. Swierzbin, F. Morris, M. Anderson, C. Klee, \& E. Tarone (Eds.), Social and cognitive factors in second language acquisition (pp. 445-457). Somerville, MA: Cascadilla Press.

Gardner, R. (2001). When Listeners Talk: Response Tokens and Listener Stance. Amsterdam: J. Benjamins Publishing.

Hey.L \& Holloway.S. (2015). Oxford advanced learner's dictionary of current English (9 th ed.). Oxford university press.

Holmes, J. (1995). Women, men, and politeness. London: Longman.

Keller, E., \& Warner, S. (1988). Conversation gambits: Real English conversation practices. LTP.

Maltz, Daniel N. \& Borker, Ruth A. (1982). A cultural approach to male-female miscommunication. In J. J. Gumpertz (Ed.), language and social identity.Cambridge; Cambridge University Press.

McCarthy, M. (1999). What constitutes a basic vocabulary for spoken communication? Studies in English Language and Literature, vol.1: 233-249.

Orestrom, B. (1983). Turn-Taking in English Conversation. Lund: Liber Forlag

Pipek, V. (2007). On backchannels in English conversation. Diploma thesis. Masaryk University

Pridham, F. (2001). The language of conversation, London: Routledge.

Tannen, D. (1990). You just don't understand. New York: William Morrow.

Thornbury, S\&Slade,D. (2006). Conversation from description to pedagogy. Cambridge: Cambrige Press.

Uchida, A. (1992). When difference is dominance: A critique of the anti-power-based cultural approach to gender differences. Language in Society, 21, 547-568.

White, S. (1989). Backchannels across cultures: A study of Americans and Japanese. Language in Society, 18:59- 76.

Yngve, V. (1970). On getting a word in Edgewise. Papers from the Sixth Regional Meeting of the Chicago Linguistic Society, 557- 567.

Young, L. (2004). Identifying units in Interaction: Reactive tokens in Korean and English conversations. Journal of Sociolinguistics 8:380- 407.

Yule, G. (2010). The study of language (4th ed.).Cambridge: Cambridge University Press.

Zimmermann, H. (1991). Speaking, listening, understanding. Stuttgart: Verlag Freies Geistesleben. 